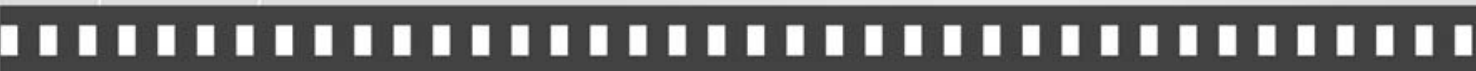
A cobertura fotojornalística do atentado à escola de Beslan em seis newsmagazines portuguesas e brasileiras

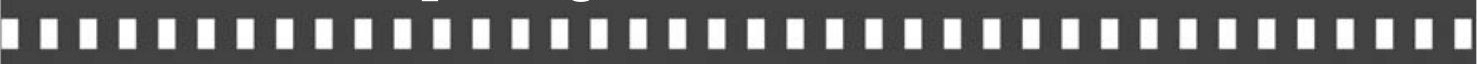

Jorge Pedro Sousa

Maria Érica de Oliveira Lima 


\title{
A cobertura fotojornalística do atentado à escola de Beslan em seis newsmagazines portuguesas e brasileiras
}

\section{Photojournalistic coverage of the attack against the school of Beslan in six Portuguese and Brazilian newsmagazines}

\author{
Jorge Pedro Sousa* \\ Maria Érica de Oliveira Lima**
}

\begin{abstract}
Resumo: Neste texto descreve-se como seis newsmagazines portuguesas e brasileiras cobriram fotojornalisticamente o atentado à escola de Beslan (Rússia) em setembro de 2004, através de uma análise quantitativa e qualitativa do discurso. Principais conclusões: 1) As fotografias foram estruturantes da narrativa e contribuíram para suportar um discurso de condenação e excomunhão dos terroristas; 2) Os fotojornalistas recuperaram padrões históricos de abordagem da realidade, enfatizando que a história contribui para moldar a forma das fotonotícias; 3) O discurso fotojornalístico é tão selectivo e enviesado como o verbal: mostra na mesma medida em que oculta.
\end{abstract}

Palavras-chave: fotojornalismo; análise de conteúdo; terrorismo; crianças.

\begin{abstract}
This work describes how six Portuguese and Brazilian newsmagazines used photojournalism to cover the attack against the school of Beslan (Russia) on september 2004, through a qualitative and quantitative analysis of the speech. Main conclusions: 1) Photos had been a structural element of the narrative and had contributed to support a speech of condemnation and excommunication of the terrorists; 2) Photojournalists used historically consolidated professional routines and standards, what shows that history helps to define the shape of news photos; 3) Photojournalism is as selective and biased as written journalism: shows in the same proportion that hides.
\end{abstract}

Key-words: photojournalism; content analysis; terrorism; children.

\footnotetext{
*Universidade Fernando Pessoa - Porto e Centro de Investigação Media \& Jornalismo - Lisboa (Portugal).

**Universidade Metodista de São Paulo.
} 


\section{Introdução}

A1 de setembro de 2004, primeiro dia do novo ano escolar, sempre assinalado com celebrações, um grupo de terroristas ${ }^{1}$ islâmicos, em que se misturavam independentistas chechenos e, possivelmente, fundamentalistas ligados à Al-Qaeda, invadiu uma escola na cidade de Beslan, na república federada russa da Ossétia do Norte, fazendo cerca de 1200 reféns, entre os quais muitas crianças, reunidas para festejar o regresso à escola.

$\mathrm{O}$ ataque foi premeditado e planeado com antecedência, pois encontraram-se provas de que os terroristas esconderam armas e explosivos na própria escola, durante obras de remodelação que decorreram em julho. Os reféns enfrentaram duras condições de cativeiro. Sem comida e sem água, as crianças foram obrigadas a beber a própria urina para não se desidratarem. Mulheres e adolescentes foram violadas pelos sequestradores, que armadilharam a escola com explosivos. A 3 de setembro, pelas 13 horas, os terroristas dispararam contra um grupo de crianças que tentou escapar, o que motivou a intervenção descoordenada e não planeada das forças russas e das milícias armadas formadas por familiares dos sequestrados. Ouviram-se duas fortes explosões, e o tecto do ginásio, onde estavam concentrados os reféns, ruiu. Os sequestradores começaram, então, a disparar indiscriminadamente sobre eles. Ainda hoje não se sabe exactamente quantas pessoas morreram em Beslan, quer por causa da queda do tecto e das execuções dos reféns, quer por causa da troca de tiros durante a intervenção das forças russas. Há estimativas que apontam para mais de quinhentas vítimas mortais, entre as quais três centenas de crianças. A notícia do sucedido rapidamente correu o mundo. Este trabalho tem por objectivo analisar comparativamente a forma como as newsmagazines de dois países lusófonos (Portugal e Brasil), cobriram fotojornalisticamente o acontecimento, tentando detectar semelhanças e diferenças na cobertura.

${ }^{1} \mathrm{O}$ atentado de Beslan enquadra-se na definição de terrorismo da ONU. 
Nos enunciados jornalísticos impressos, normalmente, os textos articulam-se com fotografias e outras imagens. As fotografias jornalísticas, além de suscitarem a atenção e interesse do leitor, criando um espaço de contemplação (ZELIZER, 2002, p.49), também contribuem para fixar os enquadramentos das histórias e para a construção de significados, proporcionando maior compreensão das notícias (TUBERGEN; MASHMAN, 1974). Hirsch (2002) e Zelizer (2002) sustentam que a fotografia se inculca mais no pensamento e na memória do que as imagens em movimento e que as fotografias de acontecimentos traumáticos ajudam as pessoas a evoluir para um estádio pós-traumático, saindo do caos em direcção à ordem. As fotos, salienta Zelizer (2002, p.49), cumprem também o seu papel jornalístico de mostrar para fazer crer.

Em consonância com o exposto, o presente trabalho tem por objectivo descrever e interpretar a forma como as newsmagazines portuguesas e brasileiras noticiaram o atentado, verificando se a cobertura foi selectiva, enviesada, dramatizada e personalizada. Tem, ainda, por objectivo desvelar os enquadramentos usados fotojornalisticamente para situar e interpretar os acontecimentos de Beslan.

Face aos objectivos equacionados, elegeu-se a análise do discurso como método de pesquisa, já que é o método que possibilita atingir-se a substância de um discurso. Para a componente quantitativa da análise, utilizou-se como unidade cada fotografia publicada em matérias que se referissem directa ou indirectamente ao atentado. A foto-informação foi, assim, classificada em número de fotos e por nível de razão, em $\mathrm{cm}^{2}$ (arredondados às unidades), por várias categorias definidas a priori, conforme é habitual neste tipo de pesquisa (cf. MELO, 1972).

A definição das categorias para a análise de conteúdo foi feita tomando em consideração que essa mesma análise procuraria testar várias hipóteses e responder às perguntas de investigação que delas emergiram, conforme se documenta no quadro seguinte: 


\section{HIPÓTESE}

\section{As fotografias jornalísticas reforçaram os enunciados verbais.}

Pergunta de pesquisa 1: Quais os enquadramentos temáticos das fotografias jornalísticas sobre o atentado e que relação se pode estabelecer, caso exista, entre os enquadramentos temáticos e o tamanho das fotos?

Pergunta de pesquisa 2: Quais as personagens nas fotografias?

\section{VARIÁVEIS:}

Quantidade de foto-informação sobre o atentado (número de fotos e espaço ocupado em $\mathrm{cm}^{2}$ ), em função do conteúdo, tamanho das fotos, em função do conteúdo; personagens presentes nas fotografias.

\section{Categorias de análise do discurso:}

Mortos e luto: Fotografias de mortos no atentado e de pessoas a chorarem as vítimas.

Atentado e socorros: Fotografias do local do atentado e das forças de segurança em acção. Socorros às vítimas.

Terroristas: Fotografias de terroristas islâmicos.

Políticos: Fotografias cujo tema central é a representação de políticos e/ou das suas actividades.

Outros atentados: Fotos de outros atentados, recuperadas com fins de enquadramento.

Outros conteúdos: Fotografias com outros conteúdos. Fotografias com conteúdos não relacionáveis com o atentado presentes em matérias que referiam este acontecimento.

\section{Quadro 1 - Demonstrativo da estrutura da análise}


Além das questões sistematizadas, definiu-se, ainda, uma derradeira pergunta de investigação, cuja resposta obrigou a uma análise qualitativa do discurso (orientada para o caso geral e não para matérias em particular) e onde se teve em conta que a linguagem visual (fotográfica) é produtiva e incapaz de espelhar a realidade e que os discursos são selectivos e focalizados, mostrando na mesma medida em que ocultam (FAIRCLOUGH, 1992; BELL; GARRETT, 1998; FOWLER, 1991):

Pergunta de pesquisa 3: De que forma as fotografias usadas para a cobertura do atentado indiciam enquadramentos e enviesamentos intencionais ou não intencionais?

Foram analisadas as primeiras edições das revistas brasileiras Veja (8 de setembro), IstoÉ (8 de setembro) e Época (6 de setembro) e das revistas portuguesas Visão (9 de setembro), Focus (8 de setembro) e Sábado (10 de setembro) publicadas logo após o atentado.

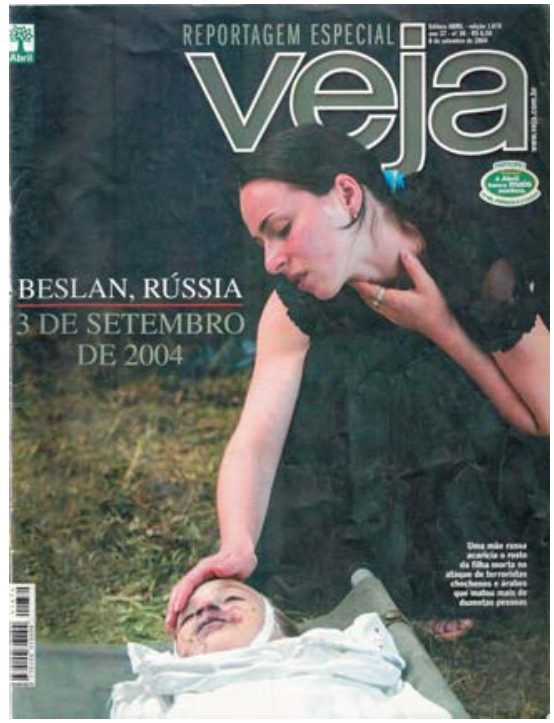

Veja (8 de setembro)

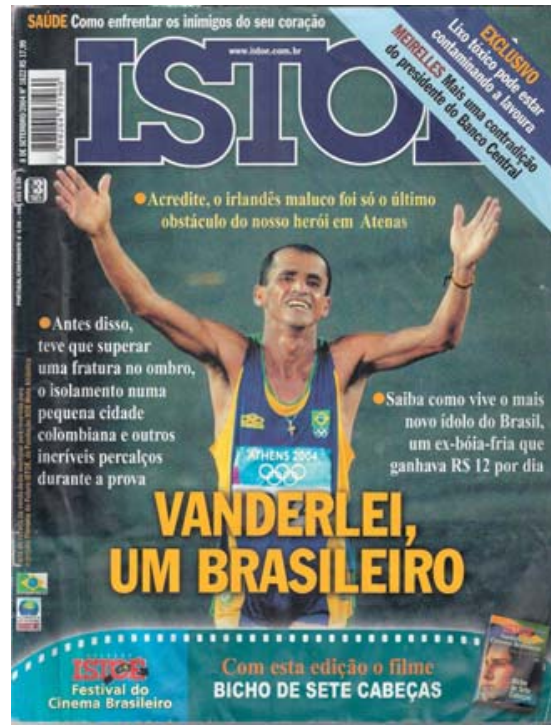

IstoÉ (8 de setembro) 


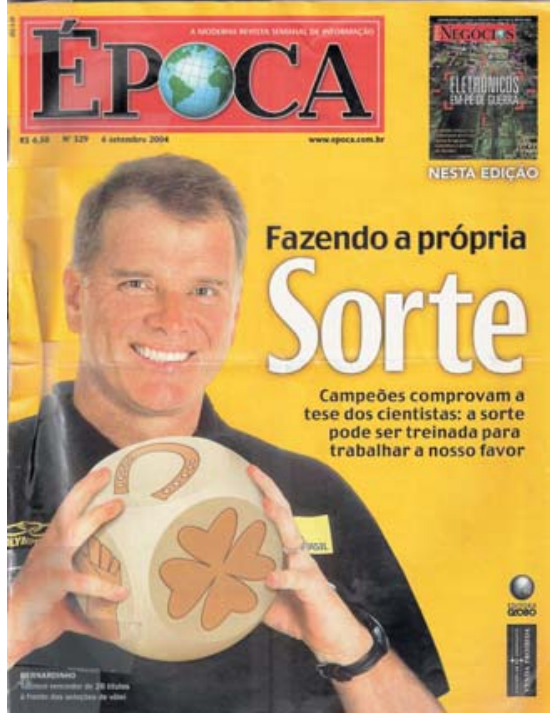

Época (6 de setembro)

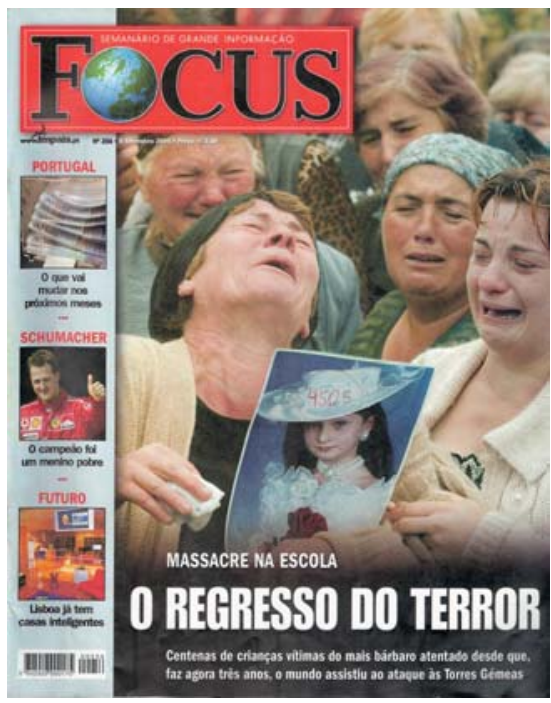

Focus (8 de setembro)

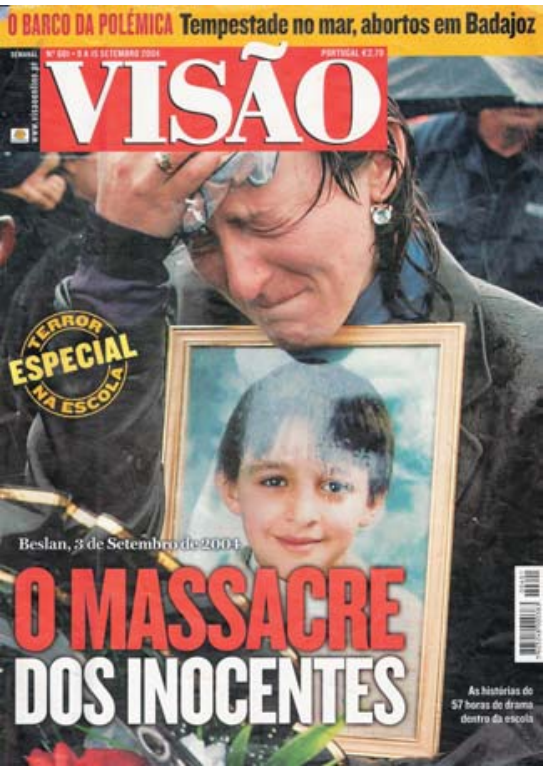

Visão (9 de setembro)

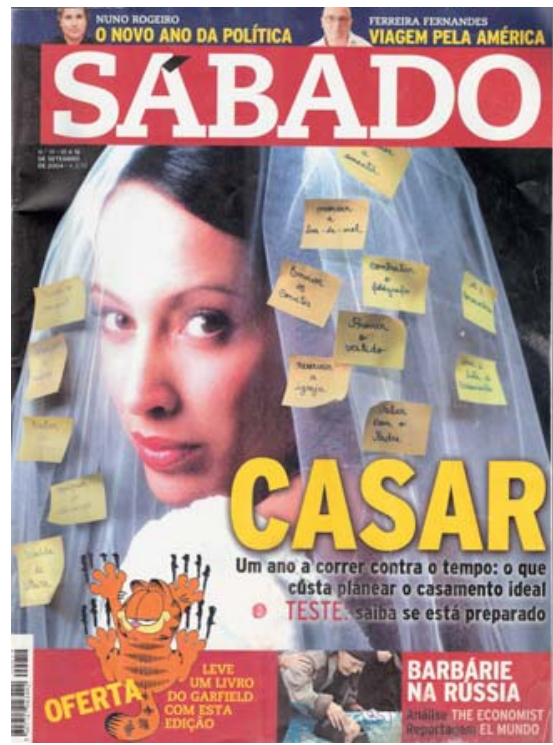

Sábado (10 de setembro) 
O objecto de estudo específico resumiu-se às matérias que referenciaram directa ou indirectamente o atentado. As matérias foram classificadas pelos dois pesquisadores/autores, sendo que a aferição de fiabilidade inter-codificadores foi, em todos os casos necessários, feita em função do conjunto de matérias codificadas.

Os dados das primeiras páginas foram contabilizados em separado, pelo que todos os dados abaixo que não mencionem o facto de se tratarem de dados recolhidos das primeiras páginas devem ser considerados como dados provenientes do corpo das revistas.

\section{Resultados e discussão}

\section{Análise quantitativa}

A análise quantitativa do discurso permitiu observar que as revistas tiveram comportamentos diferenciados, menos dependentes da nacionalidade do que de suas linhas editoriais, conforme se constata pelos dados expostos abaixo.

\begin{tabular}{|c|c|c|c|c|c|c|}
\cline { 3 - 8 } & Veja & Época & Isto $\dot{E}$ & Visão & Focus & Sábado \\
\hline Total de fotografias de notícias na capa & 1 & 1 & 1 & 1 & 4 & 2 \\
\hline Número de fotografias sobre o atentado na capa & 1 & 0 & 0 & 1 & 1 & 1 \\
\hline \% fotografias sobre o atentado na capa & $\mathbf{1 0 0}$ & $\mathbf{0}$ & $\mathbf{0}$ & $\mathbf{1 0 0}$ & $\mathbf{2 5}$ & $\mathbf{5 0}$ \\
\hline Espaço fotográfico total na capa (cm $\left.\mathbf{c m}^{2}\right)$ & 537 & 486 & 460 & 482 & 416 & 388 \\
\hline $\begin{array}{c}\text { Espaço fotográfico sobre o atentado na capa } \\
\left(\mathrm{cm}^{2}\right)\end{array}$ & 537 & 0 & 0 & 482 & 380 & 16 \\
\hline $\begin{array}{c}\text { \% espaço fotográfico da capa dedicado ao } \\
\text { atentado }\left(\mathrm{cm}^{2}\right)\end{array}$ & $\mathbf{1 0 0}$ & $\mathbf{0}$ & $\mathbf{0}$ & $\mathbf{1 0 0}$ & $\mathbf{9 1 , 3}$ & $\mathbf{4 , 1}$ \\
\hline
\end{tabular}

\section{Quadro 2 - Destaque fotográfico dado ao atentado nas primeiras páginas}

As revistas que deram mais atenção fotojornalística ao atentado nas primeiras páginas foram a Veja, a Visão (100\% do espaço ocupado por fotografias foi ocupado por uma fotografia sobre o atentado) e a 
Focus (91,3\%). Pode também dizer-se que as revistas portuguesas deram, no geral, mais destaque fotográfico ao atentado do que as brasileiras, já que todas as portuguesas "puxaram” fotos sobre o assunto à primeira página, ao contrário das brasileiras, embora na Sábado o assunto tivesse tido uma importância residual (apenas uma pequena foto referenciava o atentado, ocupando somente $4,1 \%$ do espaço concedido à foto-informação na primeira página).

Por um lado, os resultados mostram que, para a Veja, a Visão e a Focus, o atentado constituiu o assunto mais importante da actualidade, possivelmente devido à transnacionalidade e transorganizacionalidade dos critérios de noticiabilidade; por outro lado, se os meios têm a capacidade de definir, simbolicamente, a importância de um acontecimento e a gravidade de uma crise, então é visível que o atentado foi socialmente comunicado através das três revistas como sendo uma crise grave, provavelmente por estabelecer um novo patamar no terror e na conceptualização do desvio às normas (culturais) de convivência social: o patamar da violência maciça contra crianças.

Os brasileiros e portugueses leitores dessas revistas (sendo de relembrar que a Veja é a revista generalista de maior circulação no Brasil e a Visão é a newsmagazine de maior circulação em Portugal) consumiram, assim, mensagens simbolicamente similares. Porém, o atentado foi desvalorizado pelas restantes. A Sábado reservou a maior parte da "um" para uma matéria sobre o casamento, a IstoÉ reservou-a para o maratonista Vanderlei Cordeiro de Lima, considerado um herói brasileiro nas Olimpíadas de Atenas, e a Época para outro tema soft, o da "sorte". Para essas revistas, editorialmente o terror será menos compensador, como opção editorial, do que matérias ligadas ao lado "positivo" da vida. No seu segmento de mercado, o enfoque positivo e apelativo possivelmente venderá mais. 


\begin{tabular}{|c|c|c|}
\hline & $\begin{array}{c}\text { Espaço ocupado por } \\
\text { informação visual }\end{array}$ & $\begin{array}{c}\text { \% do espaço dedicado ao atentado } \\
\text { ocupado por informação visual }\end{array}$ \\
\hline Veja & 4643 & $\mathbf{5 4}$ \\
\hline Visão & 2413 & $\mathbf{2 8 , 1}$ \\
\hline Isto $\dot{E}$ & 999 & $\mathbf{4 7 , 1}$ \\
\hline Sábado & 1552 & $\mathbf{3 5 , 3}$ \\
\hline Época & 703 & $\mathbf{4 4 , 2}$ \\
\hline Focus & 2282 & $\mathbf{4 8 , 6}$ \\
\hline
\end{tabular}

\section{Quadro 3 - Relevância da informação visual sobre o atentado no corpo das revistas}

Os dados do quadro 3 evidenciam que as revistas brasileiras e a Focus foram mais gráficas e visuais do que a Visão e a Sábado na cobertura do atentado, por eventuais razões de linha editorial e design. No entanto, pode dizer-se que todas as revistas aproveitaram a informação visual, designadamente infográficos e fotografias jornalísticas, enquanto modalidades discursivas próprias e identitárias do jornalismo impresso, já que as imagens aportam informação e facilitam a compreensão. (SOUSA, 1997).

Além disso, como as imagens tendem a assinalar e destacar os enunciados verbais, pode dizer-se que a cobertura que as revistas fizeram do atentado foi enfática, no sentido de que as imagens contribuíram para reforçar, simultaneamente, a importância do acontecimento e da cobertura. As fotografias, facultando o direito a ver, permitiram também um maior entranhamento e compreensão do choque e do terror, mostrando as circunstâncias do sequestro e do ataque aos terroristas, as feições aterrorizadas das crianças, a dor profunda das mães que encontravam os seus meninos e meninas mortos e das pessoas que choravam e lamentavam a perda dos seus entes mais queridos e inocentes. 


\begin{tabular}{|c|c|c|c|c|c|c|}
\hline & \multicolumn{3}{|c|}{ Veja } & \multicolumn{3}{|c|}{ Visão } \\
\hline & N. ${ }^{\circ}$ & $\begin{array}{c}\text { Espaço } \\
\text { ocupado } \\
\left(\mathrm{cm}^{2}\right)\end{array}$ & $\begin{array}{l}\text { \% no espaço } \\
\text { ocupado por } \\
\text { informação } \\
\text { visual }\end{array}$ & N. ${ }^{\circ}$ & $\begin{array}{c}\text { Espaço } \\
\text { ocupado } \\
\left(\mathrm{cm}^{2}\right)\end{array}$ & $\begin{array}{c}\text { \% no espaço } \\
\text { ocupado por } \\
\text { informação } \\
\text { visual }\end{array}$ \\
\hline Fotografias* & 18 & 4393 & 94,6 & 21 & 2326 & 96,4 \\
\hline Infográficos & 3 & 250 & 5,4 & 2 & 87 & 3,6 \\
\hline Ilustrações & 0 & 0 & 0 & 0 & 0 & 0 \\
\hline
\end{tabular}

\begin{tabular}{|c|c|c|c|c|c|c|}
\hline & \multicolumn{3}{|c|}{ Isto $\dot{E}$} & \multicolumn{3}{|c|}{ Sábado } \\
\hline & N. ${ }^{\circ}$ & $\begin{array}{c}\text { Espaço } \\
\text { ocupado } \\
\left(\mathrm{cm}^{2}\right)\end{array}$ & $\begin{array}{l}\text { \% no espaço } \\
\text { ocupado por } \\
\text { informação } \\
\text { visual }\end{array}$ & N. ${ }^{\circ}$ & $\begin{array}{c}\text { Espaço } \\
\text { ocupado } \\
\left(\mathrm{cm}^{2}\right)\end{array}$ & $\begin{array}{c}\text { \% no espaço } \\
\text { ocupado por } \\
\text { informação } \\
\text { visual }\end{array}$ \\
\hline Fotografias* & 6 & 876 & $\mathbf{8 7 , 7}$ & 9 & 1007 & 64,9 \\
\hline Infográficos & 2 & 123 & 12,3 & 2 & 545 & 35,1 \\
\hline Ilustrações & 0 & 0 & 0 & 0 & 0 & 0 \\
\hline
\end{tabular}

\begin{tabular}{|c|c|c|c|c|c|c|}
\cline { 2 - 7 } \multicolumn{1}{c|}{} & \multicolumn{3}{c|}{ Época } & \multicolumn{3}{c|}{ Focus } \\
\cline { 2 - 7 } & \multirow{2}{*}{$\mathrm{N}^{\circ}{ }^{\circ}$} & $\begin{array}{c}\text { Espaço } \\
\text { ocupado } \\
\left(\mathrm{cm}^{2}\right)\end{array}$ & $\begin{array}{c}\text { \% no espaço } \\
\text { ocupado por } \\
\text { informação } \\
\text { visual }\end{array}$ & $\mathrm{N}^{\circ}$ & $\begin{array}{c}\text { Espaço } \\
\text { ocupado } \\
\left(\mathrm{cm}^{2}\right)\end{array}$ & $\begin{array}{c}\text { \% no espaço } \\
\text { ocupado por } \\
\text { informação } \\
\text { visual }\end{array}$ \\
\hline Fotografias* & 9 & 553 & $\mathbf{7 8 , 7}$ & 22 & 1713 & $\mathbf{7 5 , 1}$ \\
\hline Infográficos & 1 & 150 & $\mathbf{2 1 , 3}$ & 3 & 569 & $\mathbf{2 4 , 9}$ \\
\hline Ilustrações & 0 & 0 & $\mathbf{0 0}$ & 0 & 0 & $\mathbf{0}$ \\
\hline
\end{tabular}

\section{Quadro 4 - Tipo de informação visual}

Em articulação com os dados do quadro 3, o quadro 4 mostra que todas as revistas privilegiaram a fotografia entre os dispositivos de informação visual, embora tenham recorrido também aos infográficos. Pode concluir-se que a existência de imagens fortes, a capacidade que a fotografia tem de fazer do leitor uma testemunha indirecta dos acontecimentos, facultando o direito a ver, e o elevado potencial de dramatização visual do acontecimento geraram o predomínio da fotografia entre os dispositivos de informação visual, como é corrente no jornalismo impresso.

É de referir, tal como é identitário das revistas generalistas de informação geral, que todas as fotografias inseridas são coloridas (mais icônicas e realistas), com excepção de uma pequena imagem de arquivo de outro atentado, captada por uma câmara de segurança, publicada na 
Visão. Porém, algumas são fotografias coloridas de fotografias a preto-e-branco, o que, para além de apelar à ideia de sobriedade e luto, provoca uma certa sensação de estranheza.

\begin{tabular}{|c|c|c|c|c|c|c|c|c|}
\hline & \multicolumn{4}{|c|}{ Veja } & \multicolumn{4}{|c|}{ Visão } \\
\hline & $\begin{array}{c}\mathrm{N} .^{\circ} \\
\text { de fotos }\end{array}$ & $\%$ & $\begin{array}{c}\text { Espaço } \\
\left(\mathrm{cm}^{2}\right)\end{array}$ & $\%$ & $\begin{array}{c}N^{\circ} \\
\text { de fotos }\end{array}$ & $\%$ & $\begin{array}{l}\text { Espaço } \\
\left(\mathrm{cm}^{2}\right)\end{array}$ & $\%$ \\
\hline Mortos e luto & 1 & 5,5 & 530 & 12,1 & 7 & 33,3 & 754 & 32,4 \\
\hline $\begin{array}{l}\text { Atentado e } \\
\text { socorros }\end{array}$ & 11 & 61,1 & 2822 & 64,3 & 8 & 38,1 & 1326 & 57 \\
\hline Terroristas & 1 & 5,5 & 252 & 5,7 & 3 & 14,3 & 83 & 3,6 \\
\hline Politicos & 1 & 5,5 & 226 & 5,1 & 0 & 0 & 0 & 0 \\
\hline $\begin{array}{l}\text { Outros atentados } \\
\text { (arquivo) }\end{array}$ & 4 & 22,2 & 563 & 12,8 & 1 & 4,8 & 18 & 0,8 \\
\hline Outros conteúdos & 0 & 0 & 0 & 0 & 2 & 9,5 & 145 & 6,2 \\
\hline $\begin{array}{c}\text { Fotos em que } \\
\text { crianças feridas, } \\
\text { mortas ou } \\
\text { assustadas são } \\
\text { tema }\end{array}$ & 9 & 50 & 2090 & 47,6 & 13 & 61,9 & 2050 & 88,1 \\
\hline
\end{tabular}

\begin{tabular}{|c|c|c|c|c|c|c|c|c|}
\hline & \multicolumn{4}{|c|}{ Isto $\dot{E}$} & \multicolumn{4}{|c|}{ Sábado } \\
\hline & $\begin{array}{c}\mathrm{N} .^{\circ} \\
\text { de fotos }\end{array}$ & $\%$ & $\begin{array}{l}\text { Espaço } \\
\left(\mathrm{cm}^{2}\right)\end{array}$ & $\%$ & $\begin{array}{c}\mathrm{N} .^{\circ} \\
\text { de fotos }\end{array}$ & $\%$ & $\begin{array}{l}\text { Espaço } \\
\left(\mathrm{cm}^{2}\right)\end{array}$ & $\%$ \\
\hline Mortos e luto & 1 & 16,7 & 22 & 2,5 & 6 & 66,7 & 886 & 88 \\
\hline $\begin{array}{c}\text { Atentado e } \\
\text { socorros }\end{array}$ & 4 & 66,7 & 608 & 69,4 & 1 & 11,1 & 52 & 5,2 \\
\hline Terroristas & 0 & 0 & 0 & 0 & 1 & 11,1 & 52 & 5,2 \\
\hline Políticos & 0 & $\mathbf{0}$ & 0 & 0 & 0 & 0 & 0 & 0 \\
\hline $\begin{array}{l}\text { Outros atentados } \\
\text { (arquivo) }\end{array}$ & 0 & 0 & 0 & $\mathbf{0}$ & 0 & 0 & 0 & 0 \\
\hline Outros conteúdos & 1 & 16,7 & 246 & 28,1 & 1 & 11,1 & 17 & 1,7 \\
\hline $\begin{array}{c}\text { Fotos em que } \\
\text { crianças feridas, } \\
\text { mortas ou } \\
\text { assustadas são } \\
\text { tema }\end{array}$ & 4 & 66,7 & 608 & 69,4 & 3 & 33,3 & 618 & 61,4 \\
\hline
\end{tabular}

\begin{tabular}{|c|c|c|c|c|c|c|c|c|}
\hline & \multicolumn{4}{|c|}{ Época } & \multicolumn{4}{|c|}{ Focus } \\
\hline & $\begin{array}{c}\mathrm{N}^{\circ} \\
\text { de fotos }\end{array}$ & $\%$ & $\begin{array}{l}\text { Espaço } \\
\left(\mathrm{cm}^{2}\right)\end{array}$ & $\%$ & $\begin{array}{c}\mathrm{N}{ }^{\circ} \\
\text { de fotos }\end{array}$ & $\%$ & $\begin{array}{l}\text { Espaço } \\
\left(\mathrm{cm}^{2}\right)\end{array}$ & $\%$ \\
\hline Mortos e luto & 1 & 11,1 & 156 & 28,2 & 8 & 36,4 & 822 & 48 \\
\hline $\begin{array}{l}\text { Atentado e } \\
\text { socorros }\end{array}$ & 3 & 33,3 & 310 & 56,1 & 7 & 31,8 & 540 & 31,5 \\
\hline Terroristas & 2 & 22,2 & 22 & 4 & 2 & 9,1 & 149 & 8,7 \\
\hline $\begin{array}{l}\text { Politicos } \\
\end{array}$ & 0 & 0 & 0 & $\mathbf{0}$ & 3 & 13,6 & 28 & 1,6 \\
\hline $\begin{array}{l}\text { Outros atentados } \\
\text { (arquivo) }\end{array}$ & 2 & 22,2 & 51 & 9,2 & 1 & 4,5 & 24 & 1,4 \\
\hline Outros conteúdos & 1 & 11,1 & 14 & 2,5 & 1 & 4,5 & 150 & 8,8 \\
\hline $\begin{array}{c}\text { Fotos em que } \\
\text { crianças feridas, } \\
\text { mortas ou } \\
\text { assustadas são } \\
\text { tema }\end{array}$ & 3 & 33,3 & 320 & 57,9 & 8 & 36,4 & 781 & 45,6 \\
\hline
\end{tabular}

\section{Quadro 5 - Conteúdos da foto-informação sobre o atentado (tema principal das fotos)}


O elevado grau de dramatismo visual das fotos do atentado, dos mortos e do luto colocou as fotografias no centro da cobertura em todas as revistas, conforme se observa pelo quadro 5.

As crianças, assustadas ou mesmo mortas e feridas, centralizam a cobertura visual do atentado em todas as revistas, emprestando-lhe carga dramática e contribuindo, certamente, para chocar, horrorizar e revoltar os leitores.

As fotografias fixaram as expressões das crianças assustadas, as feições marcadas pela dor, os mortos em sacos de plástico (incluindo crianças), os funerais das crianças, mortas nos caixões, as crianças cheias de sangue, a angústia dos socorristas com crianças inconscientes, quiçá mortas, ao colo, a mão ensanguentada de uma criança morta segurando ainda uma pequena cruz (apelando à ideia de oposição do Cristianismo das vítimas contra o Islão dos algozes)... Pode, assim, dizer-se que todas as revistas aproveitaram, essencialmente, fotografias relacionadas com o atentado em si e as suas consequências mortais, optando por fruir do valor testemunhal das fortes imagens fotográficas do acontecimento e das vítimas e traumas que este causou. Foi, desse modo, valorizado o evento em si mesmo, os socorros, os feridos, os mortos, em detrimento de outros enquadramentos.

De destacar, porém, a recuperação de informação visual sobre outros atentados, o que contribui, a par do texto, para enquadrar o ataque contra as crianças de Beslan na longa lista de atentados dos terroristas chechenos e dos fundamentalistas islâmicos, bem como, simultaneamente, para o enquadrar na lista dos actos de violência contra crianças. Esses enquadramentos visuais, que reforçam, ademais, os enquadramentos textuais, agravam simbolicamente a culpa dos terroristas, ao mesmo tempo que criam alvos visuais de condenação e excomunhão, cuja identificação é reforçada pela inclusão de fotografias de terroristas islâmicos.

Finalmente, é de salientar que o elevado grau de choque suscitado pelas imagens poderá ter contribuído para fomentar sensações de insegurança, incompreensão e estupefacção entre os leitores. 


\begin{tabular}{|c|c|c|c|c|c|c|c|c|}
\hline & \multicolumn{4}{|c|}{ Veja } & \multicolumn{4}{|c|}{ Visão } \\
\hline & $\begin{array}{c}\mathrm{N}^{\circ} \\
\text { de fotos } \\
\text { de } \\
\text { tamanho } \\
\text { superior a } \\
\text { meia } \\
\text { página }\end{array}$ & $\%$ & $\begin{array}{c}\mathrm{N} .^{\circ} \mathrm{de} \\
\text { fotos de } \\
\text { tamanho } \\
\text { inferior a } \\
\text { meia } \\
\text { página }\end{array}$ & $\%$ & $\begin{array}{c}\mathrm{N}^{\circ} \\
\text { de fotos } \\
\text { de } \\
\text { tamanho } \\
\text { superior a } \\
\text { meia } \\
\text { página }\end{array}$ & $\%$ & $\begin{array}{c}\mathrm{N} .^{\circ} \text { de } \\
\text { fotos de } \\
\text { tamanho } \\
\text { inferior a } \\
\text { meia } \\
\text { página }\end{array}$ & $\%$ \\
\hline Mortos e luto & 1 & 5,5 & 0 & 0 & 0 & 0 & 7 & 33,3 \\
\hline $\begin{array}{l}\text { Atentado e } \\
\text { socorros }\end{array}$ & 5 & 27,8 & 6 & 33,3 & 1 & 4,8 & 7 & 33,3 \\
\hline Terroristas & 1 & 5,5 & 0 & $\mathbf{0}$ & 0 & 0 & 3 & 14,3 \\
\hline Politicos & 1 & 5,5 & 0 & 0 & 0 & $\mathbf{0}$ & 0 & 0 \\
\hline Outros atentados & 1 & 5,5 & 3 & 16,7 & 0 & 0 & 1 & 4,8 \\
\hline Outros conteúdos & 0 & 0 & 0 & 0 & 0 & 0 & 2 & 9,5 \\
\hline $\begin{array}{c}\text { Fotos em que } \\
\text { crianças feridas, } \\
\text { mortas ou } \\
\text { assustadas são } \\
\text { tema }\end{array}$ & 3 & 16,7 & 6 & 33,3 & 1 & 4,8 & 12 & 57,1 \\
\hline
\end{tabular}

\begin{tabular}{|c|c|c|c|c|c|c|c|c|}
\hline & \multicolumn{4}{|c|}{ Isto $\hat{E}$} & \multicolumn{4}{|c|}{ Sábado } \\
\hline & $\begin{array}{c}\mathrm{N}^{\circ} \\
\text { de fotos } \\
\text { de } \\
\text { tamanho } \\
\text { superior a } \\
\text { meia } \\
\text { página }\end{array}$ & $\%$ & $\begin{array}{c}\mathrm{N} \cdot{ }^{\circ} \text { de } \\
\text { fotos de } \\
\text { tamanho } \\
\text { inferior a } \\
\text { meia } \\
\text { página }\end{array}$ & $\%$ & $\begin{array}{c}\mathrm{N}^{\circ} \\
\text { de fotos } \\
\text { de } \\
\text { tamanho } \\
\text { superior a } \\
\text { meia } \\
\text { página }\end{array}$ & $\%$ & $\begin{array}{c}\mathrm{N} .^{\circ} \mathrm{de} \\
\text { fotos de } \\
\text { tamanho } \\
\text { inferior a } \\
\text { meia } \\
\text { página }\end{array}$ & $\%$ \\
\hline Mortos e luto & 0 & 0 & 1 & 16,7 & 1 & 11,1 & 5 & 55,6 \\
\hline $\begin{array}{c}\text { Atentado e } \\
\text { socorros }\end{array}$ & 1 & 16,7 & 3 & 50 & 0 & 0 & 1 & 11,1 \\
\hline Terroristas & 0 & 0 & 0 & 0 & 0 & 0 & 1 & 11,1 \\
\hline Politicos & 0 & 0 & 0 & 0 & 0 & 0 & 0 & 0 \\
\hline Outros atentados & 0 & 0 & 0 & 0 & 0 & 0 & 0 & 0 \\
\hline Outros conteúdos & 0 & 0 & 1 & 16,7 & 0 & 0 & 1 & 11,1 \\
\hline $\begin{array}{c}\text { Fotos em que } \\
\text { crianças feridas, } \\
\text { mortas ou } \\
\text { assustadas são } \\
\text { tema }\end{array}$ & 1 & 16,7 & 3 & 50 & 1 & 11,1 & 2 & 22,2 \\
\hline
\end{tabular}

\begin{tabular}{|c|c|c|c|c|c|c|c|c|}
\hline & \multicolumn{4}{|c|}{ Época } & \multicolumn{4}{|c|}{ Focus } \\
\hline & $\begin{array}{c}\mathrm{N}^{\circ} \\
\text { de fotos } \\
\text { de } \\
\text { tamanho } \\
\text { superior a } \\
\text { meia } \\
\text { página }\end{array}$ & $\%$ & $\begin{array}{c}\mathrm{N} .^{\circ} \text { de } \\
\text { fotos de } \\
\text { tamanho } \\
\text { inferior a } \\
\text { meia } \\
\text { página }\end{array}$ & $\%$ & $\begin{array}{c}\mathrm{N}^{\circ} \\
\text { de fotos } \\
\text { de } \\
\text { tamanho } \\
\text { superior a } \\
\text { meia } \\
\text { página }\end{array}$ & $\%$ & $\begin{array}{c}\mathrm{N} .^{\circ} \text { de } \\
\text { fotos de } \\
\text { tamanho } \\
\text { inferior a } \\
\text { meia } \\
\text { página }\end{array}$ & $\%$ \\
\hline Mortos e luto & 0 & 0 & 1 & 11,1 & 2 & 9,1 & 6 & 27,3 \\
\hline $\begin{array}{l}\text { Atentado e } \\
\text { socorros }\end{array}$ & 1 & 11,1 & 2 & 22,2 & 0 & 0 & 7 & 31,8 \\
\hline Terroristas & 0 & 0 & 2 & 22,2 & 0 & 0 & 2 & 9,1 \\
\hline Politicos & 0 & 0 & 0 & 0 & 0 & 0 & 3 & 13,6 \\
\hline Outros atentados & 0 & 0 & 2 & 22,2 & 0 & 0 & 1 & 4,5 \\
\hline Outros conteúdos & 0 & 0 & 1 & 11,1 & 0 & 0 & 1 & 4,5 \\
\hline $\begin{array}{c}\text { Fotos em que } \\
\text { crianças feridas, } \\
\text { mortas ou } \\
\text { assustadas são } \\
\text { tema }\end{array}$ & 1 & 11,1 & 2 & 22,2 & $\mathbf{0}$ & 0 & 8 & 36,4 \\
\hline
\end{tabular}

Quadro 6 - Dimensão das fotos e enquadramento temático 
A informação sistematizada no quadro 6 reforça as idéias atrás apresentadas de que, na totalidade das revistas, a cobertura se centrou no atentado em si, nos socorros e nos mortos e feridos. A Focus, a Sábado e, em menor grau, a Veja acentuam mais as consequências do atentado (os mortos e o luto), enquanto as restantes enfatizam mais o atentado em si e os socorros. Neste particular, o factor nacionalidade não aparenta ser relevante para destrinçar as revistas, mostrando que o jornalismo, no mundo ocidental, comunga várias opções editoriais, devido, hipoteticamente, aos valores comuns que estruturam a civilização ocidental e que cimentam a comunidade jornalística.

O elevado número de fotografias em que as crianças-vítimas são tema pode contribuir para chocar e sensibilizar o leitor. Mas essas imagens concorrem também, certamente, para a (re)construção e visualização mental do arquétipo da criança-vítima, que, com a figura do terrorista islâmico checheno, constituem os dois arquétipos mais solidamente construídos e projectados por todas as revistas analisadas. Todavia, no caso dos terroristas, o arquétipo foi construído, essencialmente, através do texto, apesar das pontuais imagens das terroristas “viúvas-negras”, de terroristas em vários teatros de operações (incluindo a escola) (Focus, Visão, Sábado) e do líder terrorista fundamentalista Chamil Bassaiev (Focus, Visão), possível mandante do atentado.

\begin{tabular}{|c|c|c|c|c|}
\hline & \multicolumn{2}{|c|}{ Veja } & \multicolumn{2}{|c|}{ Visão } \\
\hline & $\begin{array}{c}\mathrm{N}^{\circ} \\
\text { de aparições }\end{array}$ & $\%$ & $\begin{array}{c}\mathrm{N} .^{\circ} \\
\text { De aparições }\end{array}$ & $\%$ \\
\hline Mortos & 22 & 15,9 & 86 & 67,7 \\
\hline Feridos & 27 & 19,6 & 7 & 5,5 \\
\hline Sequestrados & 24 & 17,4 & 4 & 3,2 \\
\hline Populares & 25 & 18,1 & 16 & 12,6 \\
\hline Terroristas & 1 & 0,7 & 5 & 3,9 \\
\hline Politicos & 1 & 0,7 & 0 & 0 \\
\hline $\begin{array}{l}\text { Socorristas, soldados, } \\
\text { milicianos e agentes das forças } \\
\text { de segurança }\end{array}$ & 38 & 27,5 & 9 & 7,1 \\
\hline Outras & 0 & 0 & 0 & 0 \\
\hline $\begin{array}{l}\text { Crianças mortas, feridas, } \\
\text { assustadas e sequestradas }\end{array}$ & $31^{*}$ & 22,5 & $23^{*}$ & 18,1 \\
\hline
\end{tabular}

\section{Quadro 7 - Personagens nas fotos sobre o atentado}




\begin{tabular}{|c|c|c|c|c|}
\hline & \multicolumn{2}{|c|}{ Isto $\dot{E}$} & \multicolumn{2}{|c|}{ Sábado } \\
\hline & $\begin{array}{c}\mathrm{N}^{\circ} \\
\text { de aparições }\end{array}$ & $\%$ & $\begin{array}{c}\mathrm{N}^{\circ} \\
\text { De aparições }\end{array}$ & $\%$ \\
\hline Mortos & 0 & 0 & 70 & 39,3 \\
\hline Feridos & 5 & 15,6 & 0 & 0 \\
\hline Sequestrados & 3 & 9,4 & 89 & 50 \\
\hline Populares & 15 & 46,9 & 18 & 10,1 \\
\hline Terroristas & 0 & $\mathbf{0}$ & 1 & 0,6 \\
\hline $\begin{array}{l}\text { Politicos } \\
\end{array}$ & 0 & $\mathbf{0}$ & 0 & $\mathbf{0}$ \\
\hline $\begin{array}{c}\text { Socorristas, soldados, } \\
\text { milicianos e agentes das forças } \\
\text { de segurança }\end{array}$ & 9 & 28,1 & 0 & 0 \\
\hline Outras & 0 & $\mathbf{0}$ & 1 & \\
\hline $\begin{array}{l}\text { Crianças mortas, feridas, } \\
\text { assustadas e sequestradas }\end{array}$ & 5 & 15,6 & $159^{*}$ & 89,3 \\
\hline
\end{tabular}

\begin{tabular}{|c|c|c|c|c|}
\hline & \multicolumn{2}{|c|}{ Época } & \multicolumn{2}{|c|}{ Focus } \\
\hline & $\begin{array}{c}\mathrm{N} .^{\circ} \\
\text { de aparições }\end{array}$ & $\%$ & $\begin{array}{c}\mathrm{N}^{\circ}{ }^{\circ} \\
\text { De aparições }\end{array}$ & $\%$ \\
\hline Mortos & 0 & 0 & 3 & 2,6 \\
\hline Feridos & 2 & 6,7 & 13 & 11,1 \\
\hline Sequestrados & 0 & 0 & 12 & 10,3 \\
\hline Populares & 21 & 70 & 70 & 59,8 \\
\hline Terroristas & 2 & 6,7 & 2 & 1,7 \\
\hline Politicos & 0 & 0 & 4 & 3,4 \\
\hline $\begin{array}{c}\text { Socorristas, soldados, } \\
\text { milicianos e agentes das forças } \\
\text { de segurança }\end{array}$ & 4 & 13,3 & 13 & 11,1 \\
\hline Outras & 1 & 3,3 & 0 & 0 \\
\hline $\begin{array}{l}\text { Crianças mortas, feridas, } \\
\text { assustadas e sequestradas }\end{array}$ & 4 & 13,3 & 15 & 12,8 \\
\hline
\end{tabular}

\section{Quadro 7 - Personagens nas fotos sobre o atentado (continuação)}

*Grande parte dos mortos está dentro de sacos pretos, o que impede verificar se são crianças.

Consolidando interpretações já explicitadas anteriormente, os dados do quadro 7 reforçam a ideia de que a informação fotográfica das revistas se orientou para as vítimas, ficando os outros autores do acontecimento, designadamente os terroristas, relativamente na bruma. Outros agentes do espaço público informativo, em especial os detentores do poder político, também foram algo ignorados, mostrando que, pelo menos em ocasiões de choque, nem sempre os jornalistas se apegam às rotinas que intensificam a presença das “fontes oficiais” nas notícias, incluindo nas foto-notícias. Por um lado, há sempre espaços de fuga aos canais de rotina dominantes; por outro, também pode ser considerada como rotina produtiva a tentativa de obter fotografias do que aconteceu e das suas consequências. Afinal, informar, visualmente, significa, antes de mais, mostrar o que aconteceu, fazer do leitor testemunha, ainda que testemunha indirecta. 
Mortos, feridos e sequestrados do atentado de Beslan e de outros atentados (no caso das fotografias de arquivo recuperadas com novo enquadramento) constituem, com excepção da Focus, a maioria das personagens presentes nas fotos, sendo as revistas portuguesas Visão e a Sábado particularmente foto-necrófilas. Os populares, muitos deles angustiados pela dor, são outro grupo omnipresente na cobertura, que se orientou, solidariamente, para quem mais perdeu e sofreu. Socorristas, soldados e outros intervenientes no resgate surgem pouco nas imagens, devido às opções editoriais seguidas.

\section{Análise qualitativa}

\section{Primeiras páginas}

As primeiras páginas das revistas podem agrupar-se em grupos de consonância. Por um lado, as revistas que "fazem” a primeira página com o atentado: Visão, Focus e Veja; por outro lado, as que nem sequer referem o tema na primeira página: a IstoÉ e a Época. A Sábado referencia o atentado na primeira página, mas de forma tão secundária que quase poderia ser integrada no grupo das revistas que não referem o atentado na “um”. Poderá dizer-se, assim, que as opções editoriais não parecem estar vincadamente relacionadas com a nacionalidade das revistas.

As revistas que não referem o atentado e a Sábado preferem opções editoriais essencialmente positivas nas primeiras páginas: o casamento (Sábado), a sorte (Época) e o triunfo de Vanderlei (IstoÉ). As principais fotografias de primeira página das duas primeiras dessas revistas são, inclusive, ilustrações fotográficas e não fotografias de notícias. É de colocar por hipótese que algumas newsmagazines, ao procurarem seduzir o leitor proporcionando uma leitura semanal mais descontraída do que os jornais diários, privilegiem temas positivos para as capas, tal e qual fazem as revistas cor-de-rosa e do coração.

A Focus, a Veja e a Visão optaram por incluir uma única fotografia relacionada com o atentado de Beslan na primeira página. A força da fotografia impulsionou-a para o centro da cobertura e do design das duas 
revistas. A fotografia ajuda a fazer-nos testemunhas (“ver é crer”) e conecta-nos com o que presenciamos, especialmente quando está em causa a comunidade (FELMAN, 1992, p.204).

Além disso, as fotografias escolhidas pelas três revistas para referenciar o acontecimento são semelhantes, evocando a dor das mães que perdem os filhos. Na Veja, uma mãe chorosa debruça-se incrédula e dolorosamente sobre o cadáver da filha pequena. A imagem foi propositadamente escurecida, manipulada. A escuridão domina a capa, traduzindo o luto universal. Só a criança morta surge coberta por um lençol branco, cor que evoca pureza. Na Visão, outra mãe, desesperada e comovida, exibe um retrato do filho de tenra idade. O seu rosto lacrimante, desesperado, contrasta com o sorriso, para sempre apagado, do menino no retrato. A fotografia inserida pela Focus na capa é semelhante à da Visão.

As fotografias escolhidas são um elemento de condenação do atentado, pois funcionam como arquétipos universais da dor e da comoção (a dor ocasionada pela perda de crianças pequenas é reconhecível e compreensível por todos). São imagens, aliás, que relembram padrões rotineiros de abordagem fotojornalística da realidade histórica e culturalmente consolidados, pois são usadas, pelo menos, desde os anos Trinta do século XX (Guerra Civil de Espanha, invasão da China pelo Japão, II Guerra Mundial...), precisamente por serem universalmente compreensíveis. A repetição de padrões de abordagem fotojornalística da realidade evidencia que há uma acção histórico-cultural sobre as fotonotícias, como pretende Sousa (2000 b).

As fotografias escolhidas para as primeiras páginas da Focus, da Visão e da Veja reforçam as mensagens verbais. Na Veja, a homenagem às crianças assassinadas é singela. Não há propriamente um título, apenas uma referência espacial e temporal para a fotografia da capa e uma legenda: "Beslan, Rússia - 3 de setembro de 2004 - Uma mãe russa acaricia o rosto da filha morta no ataque terrorista de chechenos e árabes que matou mais de duzentas pessoas”. Na Visão, a condenação é mais explícita: "Beslan, 3 de setembro de 2004 - O Massacre dos Inocentes" [itálico 
nosso]. Esta revista inclui a imagem de um funeral na qual uma mãe chora desesperadamente o filho desaparecido no atentado. Na Focus, também se explicita, em antetítulo, que na escola de Beslan ocorreu um massacre: “Massacre na escola” [itálico nosso], sendo o título agitador: “O Regresso do Terror” [itálico nosso]. O subtítulo não deixa margem para dúvidas sobre a condenação do atentado: “Centenas de crianças vítimas do mais bárbaro atentado desde que, faz agora três anos, o mundo assistiu ao ataque às Torres Gêmeas”.

O enquadramento da Focus é, assim, evocativo, propondo que o ataque à escola seja integrado na longa lista de sangrentos atentados dos fundamentalistas islâmicos, em que pontifica o 11 de Setembro. O sentido do texto é reforçado com uma fotografia dos funerais, similar à da Visão. Se pensarmos, conforme explicitou Austin (1962) na sua teoria dos actos de fala, que os enunciados verbais não apenas geram significado mas também fazem algo, notamos que as três revistas difundem um apelo simbólico à condenação do atentado, através das palavras e das imagens, usadas, simultaneamente, para evocar e enquadrar o acontecimento e para atrair a atenção do leitor, comovendo-o e chocando-o, embora a Visão e a Focus o façam mais explícita e sensacionalisticamente do que a Veja. Na Visão, inclusive a simbologia da palavra “Massacre”, também empregue pela Focus, é realçada pela cor vermelha (do sangue). A Veja, porém, assume uma postura menos sensacionalista, mais comedida, mantendo a sobriedade harmônica da cor escura em toda a capa, incluindo no logotipo da revista (a cinza). Essa sóbria contenção da Veja tem também o sentido de homenagem às crianças assassinadas: o atentado foi um momento de dor e comoção universais, sendo desnecessários quaisquer títulos de cores berrantes.

Em suma, as três revistas têm primeiras páginas consonantes. Os enquadramentos jornalísticos do acontecimento indiciados nas primeiras páginas da Veja, Visão e Focus alimentam o sentimento colectivo e universal de incompreensão, repulsa e excomunhão dos autores de tão violento acto. Além disso, em situações de choque as palavras parecem ser insuficientes, pelo que os jornalistas necessitam de recorrer a todos os 
recursos expressivos, verbais e imagísticos, para fazerem passar a mensagem e o respectivo enquadramento.

\section{Corpo das revistas}

Fazendo-nos testemunhas indirectas dos acontecimentos, facultando-nos o direito a ver, gozando de um elevado potencial de credibilidade e constituindo um dos factores identitários da imprensa, as fotografias jornalísticas contribuem para dar sentido ao mundo (MACLEAR, 1999; SOUSA, 2000 b; ZELIZER, 2002; TUBERGEN; MASHMAN, 1974). Portanto, para se explicitarem as tendências discursivas da cobertura do atentado e o sentido global do enunciado há que ter em conta as imagens fotográficas oferecidas ao leitor e o seu enquadramento.

Antes de mais, em quatro das revistas (Veja, Focus, Época e, até certo ponto, IstoÉ), as fotografias (e os textos) foram enquadradas por faixas negras ou mesmo por grandes superfícies negras. Sabendo-se que o negro é cor de luto em Portugal e no Brasil, esse enquadramento reforça o sentido de pesar e luto, tecido a partir dos enunciados jornalísticos (texto e imagem).

Por outro lado, há a registar que a cobertura fotojornalística do atentado de Beslan obedece a uma padronização que, simultaneamente, evoca formatos fotojornalísticos históricos e reforça os enquadramentos do discurso verbal sobre os acontecimentos. Prova disso é que, no geral, as fotografias sobre os acontecimentos de Beslan abordam essencialmente seis temáticas histórica e culturalmente consolidadas (ver, por exemplo: Sousa, 2004), por vezes misturadas na mesma imagem, conforme a seguir se explicita: 1) O acontecimento e o seu cenário; 2) Mortos e feridos; 3) Socorros e operações de resgate e segurança; 4) Protagonistas constantes; 5) Manifestações de dor; e 6) Os sujeitos emotivos da acção.

1) Imagens do acontecimento e do seu cenário - As revistas publicaram dois tipos de imagens que evocam o acontecimento e o seu cenário.

Em primeiro lugar, há a considerar as imagens do acontecimento em si, havendo de dois tipos: as que mostram o momento das operações 
de resgate e socorro dos feridos, que surgem em todas as revistas, e as que foram retiradas de vídeos, mostrando a situação dentro do ginásio onde estavam concentrados os reféns. Estas imagens chocantes de crianças indefesas feitas reféns por homens armados, que a Visão e a Sábado publicam, têm a capacidade de fazer do leitor uma testemunha indirecta do acontecimento, permitindo-lhe percepcionar o sofrimento das crianças e restantes reféns durante o sequestro e levando-o a interpretar como demente, tresloucado e criminoso o acto terrorista. Permitirão, também, ao leitor evocar o que possa ter visto na televisão e, assim, reforçar a memória visual do acontecimento. Além disso, ao destacarem o sofrimento dos reféns, tornam-se congruentes e consonantes com a enunciação verbal, o que permitirá o reforço das emoções e dos significados estimulados e sugeridos pelos textos (solidariedade com as vítimas, angústia perante a situação, raiva, impotência, desejo de punição dos culpados...).

Em segundo lugar, há a considerar as imagens do cenário do acontecimento, após este ter lugar. Tal como na televisão, quando não se possuem as imagens do acontecimento, têm de se oferecer imagens de substituição, podendo ser usadas as fotografias do local (e das personagens intervenientes na acção, ainda que na qualidade de testemunhas). Fotografias do cenário devastado da escola surgem na Sábado e na Visão. Fotografias de vítimas, fotografadas pósacontecimento, na condição de testemunhas, surgem apenas na Visão.

2) Imagens dos mortos e feridos - Estas fotografias, publicadas em todas as revistas, algumas delas visualmente agressivas, funcionam como ícones do mal, pois evidenciam as trágicas conseqüências do acto terrorista. A perversidade desse acto é realçada pelo facto de a maioria dos mortos e feridos expostos nas fotografias serem crianças. Por vezes, na mesma fotografia evocam-se também as dolorosas recordações dos que ficaram. É o caso, por exemplo, da foto da mãe que acaricia o rosto da pequena filha morta, de rosto puro mas maculado pelas feridas e pelo sangue, que aparece por duas vezes na Veja, e das fotografias dos funerais em que os caixões abertos das crianças são velados pelos parentes e amigos (Sábado, Visão). É de realçar que na Visão e na Focus, por 
vezes, se ameniza o choque do leitor, pois as crianças mortas ou sequestradas são evocadas pelas respectivas fotografias (ocasionalmente a preto-e-branco) enquanto vivas, fotografias estas transportadas ou afixadas por familiares e amigos.

3) Socorros e operações de resgate e segurança - Estas fotografias, fortes, activas, tensas e graficamente apelativas, constituem, dadas as suas características, a categoria central de imagens das reportagens fotográficas da Veja, da IstoÉ e, até certo ponto, da Época, sendo também usadas na Visão e na Focus. Nelas repetem-se, insistentemente, vários motivos, nomeadamente adultos transportando ao colo crianças feridas, assustadas, em alguns casos moribundas, talvez mesmo mortas. Noutras imagens, as crianças gritam, ou bebem, sequiosas, depois de terem sido salvas. Noutros casos ainda, observam-se instantes dos combates das forças russas de socorro com os terroristas islâmicos. O aspecto algo caótico das operações é compensado com a visão de que pelo menos algumas crianças estão sãs e salvas. Todas elas são imagens que têm o valor testemunhal do documento, mas também indiciam que a sociedade continuou a funcionar, o que contribuirá para a tranquilização social e ajudará a reconduzir as pessoas para a segurança e normalidade da vida quotidiana. São, igualmente, imagens que contribuem para que se vença a dissonância cognitiva entre a experiência do acontecimento e o que se pensava sobre o conflito no Cáucaso antes do atentado ter ocorrido, conduzindo a um novo estádio de equilíbrio entre a experiência do quotidiano (o agir) e o pensamento.

4) Protagonistas constantes - Vítimas, forças de segurança, civis afectados, líderes políticos e terroristas tendem a ser os protagonistas constantes da cobertura fotojornalística de atentados terroristas (ver, por exemplo: SOUSA, 2004 b). Por isso, além das fotografias de vítimas, de civis afectados e de agentes das forças de segurança (em vários casos acompanhados por civis), as revistas publicaram imagens dos terroristas e do presidente Putin, entre outros personagens. As fotografias desses actores inseridas nos enunciados das revistas destacam a sua importância simbólica no contexto do enunciado e, portanto, reforçam o seu 
protagonismo. Para além disso, a forma como os protagonistas são fotograficamente representados (gestos, expressões, acções...) contribuirá para a construção de imagens mentais dos sujeitos e dos acontecimentos por parte do leitor.

A Visão não publicou fotos do presidente Putin, mas, em contrapartida, inseriu várias imagens de terroristas chechenos, sendo que numa delas aparece o único terrorista capturado vivo, de ar assustado; noutra aparece uma tenebrosa “viúva negra”; e noutra ainda aparece o terrorista nacionalista-fundamentalista islâmico Chamil Bassaiev (de camuflado, mas pose serena), tido pelo Kremlin como o homem por trás do atentado. Bassaiev, na fotografia, quase se transfigura num homem normal e calmo, apesar do camuflado indicar as circunstâncias extraordinárias em que foi fotografado.

A Focus insere, por seu turno, uma fotografia do terrorista Chamil Bassaiev, muito semelhante àquela que foi publicada pela Visão, o que hipoteticamente, favorecerá uma leitura de imagem idêntica à suscitada pela foto Visão. Apesar de cada leitor, em última instância, construir, individualmente, um sentido para as imagens, a ideia forte que parece emergir das fotografias de Bassaiev publicadas quer pela Focus quer pela Visão é, assim, contrária à do texto, pois se no texto se explicita que terá sido ele o "anormal” mandante do atentado de Beslan, nas fotografias ele parece um sujeito bondoso, calmo e compreensivo.

O presidente Putin surge fotograficamente representado na Focus e na Veja. Nas fotos inseridas em ambas as revistas, Putin surge igual à imagem que foi cultivando: circunspecto, frio e grave, em pose de estadista e pensador. Numa das fotografias inseridas na Focus, observa-se a atitude mais humanamente emotiva do presidente russo: uma carícia a uma criança ferida, num hospital. Uma ideia poderá ser construída pelo leitor a partir das imagens: Putin é um homem frio e determinado contra o terrorismo, embora se preocupe humanamente com as pessoas do seu povo.

A Veja insere, consonantemente com o seu discurso de associação entre o atentado de Beslan e a Al-Qaeda, uma foto de Bin Laden. 
Na Focus, a repercussão universal do atentado é marcada pela inclusão de pequenas fotografias do presidente Bush e do papa João Paulo II, o que se torna mais relevante pelo facto de mais nenhuma das revistas ter incluído imagens de outros líderes políticos ou religiosos.

Os restantes protagonistas constantes dos atentados, ou seja, as vítimas (muitas delas mortas) e as forças de segurança, surgiram em fotografias publicadas em todas as revistas (só na Sábado não se vêem agentes das forças de segurança, embora sejam evocados num infográfico). De facto, eles foram os protagonistas do atentado em si e das operações de socorro, facto que repercutiu na cobertura fotojornalística dos acontecimentos de Beslan. Nesse contexto, é de referir que apenas a Visão publicou uma fotografia individual de uma das vítimas do sequestro, obtida já depois do drama, em condições de serenidade. Essa fotografia, no entanto, serviu mais para dar um rosto às informações disponibilizadas pela vítima (uma adolescente) e à história que ela contou, credibilizando e humanizando o trabalho do repórter, do que para acrescentar informação visual à narrativa.

Pode dizer-se que as revistas analisadas neste trabalho seguiram uma política editorial fotojornalística parcialmente dissemelhante e parcialmente similar no que respeita à presença dos "protagonistas constantes" no enunciado fotojornalístico, permitindo evidenciar que os discursos mostram, focalizam e evidenciam na exacta medida em que ocultam. Ao lerem-se todas as revistas e verem-se todas as fotografias, ficamos com uma noção bastante mais precisa dessa realidade, pois algumas revistas mostram o que outras ignoram e vice-versa. Provavelmente, aliás, muito mais ficou por registar visualmente: nenhuma revista publicou, por exemplo, fotografias dos agentes das forças de segurança mortos e feridos no ataque, apesar de, metaforicamente, eles também terem pago um alto preço: o da vida. Também nenhuma revista publicou fotografias dos terroristas mortos, que poderiam “mostrar” até onde pode conduzir o fanatismo religioso pessoal.

5) Fotografias de manifestações de dor - Fotografar as pessoas expressando a sua dor constitui um dos padrões fotojornalísticos de 
abordagem de assuntos chocantes (SOUSA, 2000 b; SOUSA, 2004 b). Assim, fotografias de pessoas chorando, desesperadas, os seus mortos não faltaram na totalidade das revistas. Os mortos, nomeadamente crianças, estão fisicamente presentes nalgumas fotos; noutras estão representados pelas fotografias a que as pessoas se agarram, como se quisessem restituilas à vida. É o retrato fotográfico da insanidade de uma morte absurda...

6) A busca dos sujeitos emotivos da acção - Os fotojornalistas, para construírem sentido para as imagens, tentam encontrar no cenário a fotografar os sujeitos que melhor transmitam uma ideia concreta, pelos seus gestos, expressões ou acções. Essa opção é comum a todas as fotografias publicadas nas revistas, reflectindo rotinas e conviç̧ões profissionais. É a mãe que se despede dolorosamente da sua menina pela última vez, a mãe que se agarra à fotografia do seu menino morto no respectivo funeral, o presidente Putin que acaricia a criança ferida e sem reacção num hospital, os militares e civis que resgatam as crianças e também transportam aquelas que estão mortas e feridas, as crianças que choram e gritam, etc.

Há um aspecto em que as revistas portuguesas diferiram das brasileiras na abordagem fotojornalística dos acontecimentos de Beslan. As revistas brasileiras inseriram, maioritariamente, fotografias das operações de resgate e de socorro, que enfatizaram a fragilidade das crianças resgatadas, enquanto as revistas portuguesas, sem ignorarem essa dimensão do acontecimento (com exclusão da Sábado, que não inseriu, sequer, fotografias das operações de resgate), tiveram uma cobertura visualmente mais multifacetada e graficamente menos agressiva.

É ainda de registar que, na Visão, surge uma imagem de uma das jornalistas que alegadamente o Kremlin tentou silenciar, Anna Politkoyskaia. Trata-se de uma mensagem de valorização da liberdade de imprensa, valor sagrado dos jornalistas nos países democráticos (ver, por exemplo: TRAQUINA, 2004).

Finalmente, a semelhança dos conteúdos e formas das fotografias jornalísticas ao longo do tempo indiciam que o fotojornalismo actual é um produto da história (SOUSA, 2000 b). Por isso, e também porque os (foto)jornalistas recorrem a rotinas cognitivas que dominam para 
organizar as ideias e fazer sentido do mundo (STOCKING ; GROOS, 1989, p.4), repetem-se as rotinas de produção fotojornalística e os padrões de cobertura ao longo do tempo. Em conseqüência, também a cobertura do atentado de Beslan se ancorou nas imagens do local e da acção.

\section{Considerações finais}

A primeira grande consideração a extrair deste trabalho é a de que, no geral, o factor nacionalidade não parece ter tido influência decisiva nos conteúdos fotojornalísticos das revistas. Por outras palavras, as revistas tiveram comportamentos dissonantes e consonantes que, com poucas excepções, não parecem ter sido provocados pelo factor "nacionalidade", já que, tendo em conta as variáveis observadas, as revistas, normalmente, não podem ser agrupadas em dois grupos, consoante a nacionalidade das mesmas.

Em segundo lugar, pode dizer-se que a fotografia foi usada, estruturalmente, por todas as revistas. As fotografias tiveram, em todas as publicações, o papel de reforço dos enunciados verbais (condenatórios do terrorismo e dos terroristas), já que deram ao leitor a hipótese de (re)ver em imagens fixas as vítimas (em particular as crianças), os esforços para as salvar e as conseqüências do atentado e, conseqüentemente, deram-lhe também a oportunidade de se comover com o cenário e participar na condenação e excomunhão dos perpetradores do acto. Porém, visto de outro prisma, a espectacularização de algumas fotos e de alguns textos e a sua centralização na criançavítima, social e culturalmente determinada, contribui também para as notícias venderem, pois neste aspecto, tragicamente, as “melhores vítimas" são as crianças.

Finalmente, os dados da análise qualitativa mostram que as revistas não só não conseguem furtar-se à produtividade da linguagem visual 
como também, em ocasiões traumáticas como a do atentado de Beslan, orientam (enviesam) o discurso numa determinada direcção, mostrando tanto como ocultam. Por exemplo, nenhuma das revistas publicou fotografias dos terroristas mortos nem mesmo dos elementos das forças russas mortos e nenhuma revista aprofundou fotojornalisticamente, em jeito contextual, a situação na Chechénia (só há duas pequenas fotos evocativas da acção destrutiva das forças russas na Chechénia, publicadas na Focus).

Com o texto e as fotografias, favorece-se a (re)construção e visualização mental dos conceitos projectados pelo discurso. Simbolicamente, demarca-se também, ao nível dos valores, uma fronteira entre o bem e o mal. É uma visão discursiva que revela o quanto as sociedades rejeitam, colectivamente, aquilo que as ameaça. A avaliar pela condenação do atentado feita explicitamente pelas revistas a partir da evocação da criança-vítima, com maior intensidade na Veja, na Focus e na Sábado, esses discursos de rejeição, elaborados no contexto de determinantes culturais comuns à Civilização Ocidental, parecem assumir, incluse, a condição de discursos hegemónicos em ocasiões especiais, como as traumáticas. É óbvio que para alguns muçulmanos os assassinos fundamentalistas islâmicos do 3 de Setembro, tal como os do 11 de Setembro ou os do 11 de Março, podem ser vistos como “combatentes da liberdade”, mas à luz da cultura ocidental são percepcionados como bárbaros homicidas que ameaçam a estrutura e o modo de vida da civilização ocidental. Não é o poder que define, nestas circunstâncias, o discurso hegemónico, como pretendem autores neo-marxistas ou muçulmanos (estranha aliança de enquadramentos!), como Karim (2002), mas sim a própria sociedade, colectivamente, em luta pela sua própria sobrevivência e pela manutenção do seu modo de vida.

O jornalismo, imerso nessa sociedade, ecoa os seus valores e as suas visões do mundo, apesar de, paradoxal e simultaneamente, dar espaço quer às posições dos que desejam a destruição do sistema quer aos discursos consolidantes do sistema e das normas de convivência em sociedade. 


\section{Referências}

AUSTIN, John Langshaw. How to do things with words. Oxford: Oxford University Press, 1962.

BELL, Allan; GARRETT, Peter (Ed.). Approaches to media discourse. Oxford: Blackwell Publishers, 1998.

FAIRCLOUGH, Normando. Discourse and social change. Cambridge: Polity Press, 1992.

FELMAN, Shoshana: The return of the voice: Claude Manzmann's Shoah. In: FELMAN, S.; LAUB, D. (Ed.). Testimony: crises of witnessing in literature, psychoanalysis and history. New York, Routledge, 1992.

FOWLER, Roger. Language in the News: discourse and Ideology in the Press. London: Routledge, 1991.

HIRSCH, Marianne. The day time stopped. Chronicle of Higher Education, v.25, p.B11, jan. 2002.

KARIM, H. Karim. Making sense of the "Islamic Peril": Journalism as cultural practice. In: ZELIZER, Barbie; ALLAN, Stuart (Ed.). Journalism after September 11. New York:

Routledge, 2002. p.101-116.

MACLEAR, Kyo. Beclouded visions: Hiroshima-Nagasaki and the art of witness, Albany: State University of New York Press, 1999.

MELO, José Marques de. Estudos de jornalismo comparado. São Paulo: Pioneira, 1972. 
SOUSA, Jorge Pedro. Fotojornalismo performativo: o serviço de fotonotícia da Agência Lusa de Informação. Porto: Universidade Fernando Pessoa, 1997.

. As notícias e os seus efeitos. Coimbra: Minerva, 2000 a.

\section{. Uma história crítica do fotojornalismo ocidental.}

Florianópolis: Letras Contemporâneas, 2000 b.

. O dia depois: a reacção da imprensa portuguesa ao atentado de 11 de março de 2004 em Madrid. In: CONGRESSO LUSOGALEGO DE ESTUDOS LINGUISTICOS, 3., 2004, Santiago de Compostela. Comunicação ao III Congresso Luso-Galego de Estudos Jornalísticos. Santiago de Compostela: Universidade de Santiago de Compostela, 2004.

STOCKING, S. H.; GROSS, P. H. How do journalists think: a proposal for the study of cognitive bias in newsmaking. Bloomington: ERIC Clearinghouse on Reading and Communication Skills, 1989.

TRAQUINA, Nelson. As notícias. Revista de Comunicação e Linguagens, Lisboa, v.8, p. 29-46, 1988.

TUBERGEN, G. N.; MASHMAN, D. L. Unflattering photos: how people respond. Journalism Quarterly, Urbana, v.51, n.2, 1974.

ZELIZER, Barbie. Photography, journalism, and trauma. In: ZELIZER, Barbie; ALLAN, Stuart. (Ed.). Journalism after September 11. New York: Routledge, 2002, p.48- 68.

ZELIZER, Barbie; ALLAN, Stuart. When trauma shapes the news. In: . (Ed.). Journalism after September 11.New York:

Routledge, 2002, p.1-24. 